\title{
El Compendium musicae y la confesión de Descartes
}

\author{
Mario Edmundo Chávez Tortolero
}

\section{Introducción}

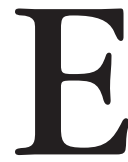

1 Compendium musicae es un texto menor en el corpus cartesiano. Poco se ha hecho para valorarlo e interpretarlo. Reducido a dato biográfico, la primera obra de Descartes parece prescindible en lo que respecta al estudio de la filosofía. En efecto, no fue gracias al Compendium musicae que Descartes se convirtió en la figura de la modernidad que sigue siendo en la actualidad. Sabemos que el texto fue redactado en 1618 como regalo para Isaac Beeckman, en vísperas del año nuevo. ${ }^{1}$ El autor se encontraba en Breda, en donde no era más que un joven docto y talentoso, tan versado en los razonamientos filosóficos más abstractos como en las figuras literarias más expresivas, no obstante, un joven desconocido en ese lugar al que acababa de llegar. En tal situación de evanescencia dejó testimonio de su potencial con una teoría musical sui generis que combina el rigor de los

${ }^{1}$ El periodo de la vida de Descartes que va de la salida del colegio La Flèche a la entrada al ejército es difícil de datar. Según Baillet, sale del colegio en 1612, y en 1614 se retira a Saint-Germain para reflexionar en soledad; y en 1617 se alista en el ejército (Adrien Baillet, La vie de monsieur Descartes. París, Daniel Horthemels, 1691, pp. 3744). Gaukroger sostiene que Descartes no sale del colegio sino hasta 1614 y se gradúa en 1616, en Poitiers, para entrar al ejército en 1618. En efecto, el periodo "entre la salida de La Flèche y la entrada a la Universidad de Poitiers, es algo misterioso" (Stephen Gaukroger, Descartes. An Intellectual Biography. Oxford, Clarendon, 1997, p. 62). En todo caso, Descartes se habría enlistado en el ejército de Mauricio de Nassau con motivo de la Guerra de los Treinta Años (René Descartes, "Discourse de la méthode", segunda parte, en Ouvres de Descartes. Ed. de Charles Adam y Paul Tannery. París, J. Vrin, 1996, vol. VII). Cuando inició el conflicto armado ya iba de regreso a Francia. Pero en su corta carrera de soldado consiguió una amistad muy prolífica, en términos científicos y diplomáticos, con Isaac Beeckman, junto con ciertas dudas profundísimas, tres sueños reveladores e ideas definitivas para el resto de su obra. 
matemáticos con el refinamiento de los humanistas y la sistematicidad de los escolásticos con la libertad renacentista.

Sabemos que Descartes procuró esconder esta obra de juventud. Su primer biógrafo, Adrien Baillet, habría caído en la paradoja de exponer un Tratado de música que no debió conocer, ${ }^{2}$ ya que fue escrito sólo para un lector ya fallecido. La voluntad del autor no disuadió a su primer biógrafo de exponer algunos fragmentos en los que resalta el carácter críptico del texto, más que su peculiar contenido. Esta referencia, así de truncada, imprecisa y paradójica, ha dominado por siglos. Ya en el siglo $\mathrm{xx}$, el historiador de la estética Wladyslaw Tatarkiewicz decretará que "[Descartes] no pertenece al grupo de los grandes filósofos que reservaron en sus programas y sistemas filosóficos un lugar importante para la estética". ${ }^{3}$

\section{Situación hermenéutica}

La filosofía cartesiana quedó plasmada en textos canónicos como el Discurso del método (1637), ${ }^{4}$ las Meditaciones metafísicas (1641), los Principios de la filosofía (1644) y Las pasiones del alma (1649). Pero es en sus textos de juventud (antes de que su pensamiento se consolidara como un sistema completo y unificado) en donde puede apreciarse la gestación de su doctrina ${ }^{5}$ y

${ }^{2}$ A. Baillet, op. cit., p. 46.

${ }_{3}^{3}$ Wladyslaw Tatarkiewicz, Historia de la estética. La estética moderna. Trad. de Antonio Moreno. Madrid, Akal, 1991, vol. 3, p. 465.

${ }^{4}$ Hay que notar que el mismo Descartes se ocupó de resaltar la importancia de sus primeros pensamientos autónomos en su obra de madurez. Por ejemplo, en el Discurso del método dice lo siguiente: "En aquel entonces -tras abandonar los libros para viajar y elaborar su primera obra- me encontraba en Alemania [...] con toda la tranquilidad necesaria para entregarme a mis pensamientos" (R. Descartes, "Discourse de la méthode", en Ouvres de Descartes, vol. viI, segunda parte). Sabemos que además de la guerra, las dudas y la nueva ciencia, la música sería una de sus principales preocupaciones en aquel entonces. No es de extrañar que sacara una conclusión de carácter estético a partir de dichos pensamientos: "no suele haber tanta perfección en las obras compuestas de varias partes y hechas por la mano de varios maestros, como en aquellas que han sido trabajadas de una vez" (ibid., p. 15). Así como Aristóteles habría notado que la perfección de la tragedia depende de la unidad de la trama, Descartes infiere que la unidad de un pensamiento sistemático es fundamental para alcanzar la perfección de la sabiduría y el conocimiento humano. Así, pues, el padre de la filosofía moderna se apoyaría en un principio poético para iniciar la empresa que revolucionaría tanto a las ciencias como a la filosofía.

${ }^{5} \mathrm{Cf}$. Alejandra Velázquez, "De la filantropía en la ciencia cartesiana", en De la filantropía de las pasiones. México, unAM, 1994. Para un estudio pormenorizado de la filosofía cartesiana con respecto a sus obras de juventud: Vid. Genevière Rodis-Lewis, Le dèveloppement de la pensé de Descartes. París, J. Vrin, 1997. 
apreciarla a la luz de los problemas y matices propios de la crisis histórica, científica y cultural que se vivía en aquel entonces. Es el joven Descartes quien "nos ilustra -en palabras de Antonio Negri- un proceso de crisis, muy parecido al actual". 6

El proceso de crisis se hace patente en varios opúsculos cuya redacción suele datarse entre 1618 y 1620: Olympica, Experimenta, Studium Bonae Mentis, Cogitatione Privatae. ${ }^{7}$ El Compendium musicae (1618) resalta de este conjunto por dos razones. Primero, porque se trata de un texto completo; más que un opúsculo es una obra propiamente dicha. Segundo, porque aborda un tema sui generis en el marco de la filosofía cartesiana. En efecto, tras de completar su primera obra, Descartes no volverá a ocuparse de la música más que para dudar de su empresa juvenil y confesar la gravedad de sus limitaciones en la materia, como que no era capaz de distinguir una quinta de una octava, que nunca aprendió a cantar escalas, y que se consideraba prácticamente sordo en cuestiones musicales. ${ }^{8}$ Es a partir de sus propias palabras, en particular de su correspondencia con Marin Mersenne e Isabel de Bohemia, ${ }^{9}$ que ha surgido la idea de que un pensador como él no desearía ocuparse de asuntos tan subjetivos e irracionales como son las cuestiones estéticas. ${ }^{10}$

Hay que decir que la empresa del Compendium musicae no tendría ningún sentido si el autor fuese de la opinión de que la música es completamente subjetiva e irracional. Es posible que el mismo Descartes cambiara de opinión tras completar este texto. En todo caso, si pretendemos afirmar o negar que el pensamiento de Descartes cambió entre la juventud y la madurez, al menos en lo que respecta a las cuestiones estéticas, es menester elaborar una interpretación satisfactoria de su teoría musical a la luz de la filosofía cartesiana en general. En ese tenor, el Descartes anterior al Discurso del método resulta significativo por cuanto su estudio permite problematizar -si no es que

${ }^{6}$ Antonio Negri, Descartes político. Trad. de María Malo de Molina. Madrid, Akal, 2008, p. 10.

${ }^{7}$ Vid. Henri Gouthier, Les premiers penseés de Descartes. París, J. Vrin, 1970.

${ }^{8} \mathrm{Cf}$. Rudolf A. Rasch, "Six seventeenth-century dutch scientist", en Victor Coelho, ed., Music and Science in the Age of Galileo. Dordrecht/Boston/Londres, Kluwer Academic, 1992, p. 196.

${ }^{9}$ Daniel Garber sostiene que la correspondencia con Isabel de Bohemia es indispensable en lo que respecta al problema de interacción o comunicación entre sustancias ( $c f$. Daniel Garber, Descartes Embodied. Reading Cartesian Philosophy through Cartesian Science. Nueva York, Universidad de Cambridge, 2001, parte III, cap. 8). Más adelante abordaremos este problema.

${ }^{10}$ Vid. Brigitte van Wymeersch, "L'esthètique musicale de Descartes et le cartésianisme", en Revue Philosophique de Louvain, cuarta serie, 1996, t. 94, núm. 2, pp. 271-293. Van Wymeersh ofrece un análisis detallado sobre la estética musical de Descartes en su correspondencia con Marin Merssene e Isabel de Bohemia. 
comprobar o desechar- la supuesta unidad sistemática de su pensamiento. Además, desde un enfoque más amplio, el presente trabajo se justifica por el hecho de que constituye un elemento de reflexión, comprensión e interpretación de problemas estéticos fundamentales en el marco del nacimiento de la filosofía moderna.

\section{Planteamiento del problema}

Si bien es cierto que el Compendium musicae inicia con la distinción entre objeto (el sonido), medio (las afecciones sonoras) y fin (nosotros o las mentes) de la música, en el desarrollo del texto no es claro si los términos utilizados corresponden a fenómenos físicos, a proporciones numéricas o a determinados afectos; si son definidos con base en la naturaleza del sonido en tanto que sustancia extensa o dependen de cómo es que la mente siente y piensa de manera racional. En lugar de las dudas y precauciones que caracterizan a la filosofía cartesiana en lo referente al conocimiento del mundo externo, ${ }^{11}$ en este texto encontramos una petición de principio bastante problemática: para teorizar sobre la música hemos de admitir que la fuerza del sonido musical es comunicada a nuestras almas a través de los oídos, es decir, que existe alguna relación o comunicación entre la extensión y el pensamiento.

En lo que sigue trataremos de comprender el problema que acabamos de plantear. Para tales efectos, se identifican algunas características generales de la filosofía cartesiana que pueden observarse en el texto que nos ocupa. Después se ofrece un resumen del contenido. En tercer lugar se presenta el problema que identificamos como "la confesión de Descartes". Finalmente, se propone una interpretación alternativa del dualismo y del papel de la teoría musical en la filosofía cartesiana.

\section{Características de la filosofía cartesiana en el Compendium musicae}

La influencia del Compendium musicae en la teoría musical moderna es una evidencia histórica. ${ }^{12}$ La ubicación del texto en el marco de la filosofía cartesiana implica una labor constante de análisis, interpretación y discusión filosófica.

${ }^{11}$ Vid. Laura Benítez, El mundo en René Descartes. México, UNAM, 1993, p. 51.

${ }^{12}$ La empresa del Compendium no ha de ser vista como un fracaso si consideramos la influencia que tuvo en músicos y teóricos de la música de la talla de Isaac Beeckman, Marin Mersenne, Wolfgang Caspar Printz, Joseph Sauveur y Jean-Philippe Rameau (David Damschroder y David Russell, Music Theory from Zarlino to Schenker. And Bibliography and Guide. Nueva York, Pendragon, 1990). 
En ese sentido, es pertinente señalar tres rasgos característicos de la filosofía cartesiana que pueden observarse en el texto que nos ocupa.

\section{Deductibilidad}

La filosofía cartesiana se despliega a partir de principios considerados fundamentos en tanto que no dependen de nada y todo lo demás depende de ellos. ${ }^{13}$ La deductibilidad de los mismos consiste en la posibilidad de justificar proposiciones y sacar conclusiones a partir de su evidencia. Al respecto, es interesante notar que:

$i$. La estructura argumentativa del Compendium musicae es eminentemente deductiva. En general, las afirmaciones que contiene se justifican por lo dicho u observado anteriormente, de manera que la verdad o falsedad de toda la teoría tendría que derivarse de un conjunto limitado de observaciones, proposiciones y argumentos fundamentales.

ii. El tratamiento del sonido se estructura según la naturaleza del mismo, como si el sonido se comportara de manera deductiva por su propia naturaleza. La disposición de los capítulos representa, pues, la forma en la que naturalmente se comportaría el objeto a tratar. Tras emitir un sonido cualquiera o unísono, siendo que la materia tiende a dividirse por sí misma, en efecto, la intensidad del sonido cambiará conforme pase el tiempo. Primero se divide en dos partes iguales, de donde surge la octava (1/2). A continuación, se divide la octava y surge la quinta (2/3). Inmediatamente después se divide la quinta y surge el ditono (4/5). Y así es como van surgiendo todos los intervalos sonoros relevantes en la teoría musical. La naturaleza de la quinta es deducida de la naturaleza de la octava; la naturaleza del ditono de la naturaleza de la quinta; etcétera. Observamos, pues, que cada elemento va apareciendo en la teoría según el orden de génesis y perfección que le corresponde por naturaleza.

iii. El desarrollo de los contenidos es bastante breve. El autor pretende que se realicen más deducciones a partir de los fundamentos que propone, ya sea para confirmar lo dicho o para descubrir nuevas verdades al respecto, de manera que el texto puede ser visto como un conjunto de fundamentos listos para ser desarrollados por alguien más. Observamos, pues, el "fruto principal" de la filosofía cartesiana que será identificado por Descartes en los Principios de la filosofía: "El último y principal fruto de estos Principios es que, al cultivarlos, se descubrirán muchas verdades que yo no he explicado en los mismos". ${ }^{14}$

${ }^{13} C f$. R. Descartes, "Carta del autor al traductor de los principios de la filosofía", en Los principios de la filosofía. Madrid, Alianza, 1995.

${ }^{14}$ Ibid., p. 18. 


\section{Matematización}

Una parte considerable de los razonamientos del Compendium consiste en operaciones matemáticas: sumas, restas, divisiones y multiplicaciones. Así, pues, se trata de entender a la música mediante la "matematización" del sonido. Sin embargo, hay que notar lo siguiente:

$i$. Descartes pretende comprender las magnitudes y fenómenos sonoros mediante cantidades y operaciones aritméticas; pero no se trata de cualesquiera cantidades y operaciones, sino sólo de aquellas que permiten identificar sonidos y fenómenos relevantes en términos musicales. Para matematizar el sonido se requieren, pues, criterios independientes de la naturaleza del sonido por cuanto su determinación depende del objetivo o finalidad de la música, consistente en la satisfacción del escucha. Dichos criterios son reducibles a tres, a saber: 1) que la semejanza o simpatía es más valiosa que la desemejanza o antipatía, 2) que la facilidad es más agradable que la dificultad y 3) que la variación es preferible a la repetición.

ii. Los criterios anteriores permiten matematizar el sonido y mantener la cohesión y la validez de toda la teoría musical. Pero no pueden ser justificados mediante razonamientos deductivos. Aunque pueden ser intuidos o justificados por sentido común, quizá inducidos mediante ilustraciones. Por ejemplo, con respecto al primer criterio mencionado, dice Descartes que "la [voz] del mejor amigo es, sin duda, más agradable que la del enemigo, gracias a la simpatía y la antipatía de los afectos; por eso dicen que la piel de oveja, tensada en un tambor, va a enmudecer, si es tocada mientras la de lobo resuena en otro tambor". 15

iii. La asignación de valores numéricos a intervalos sonoros (consonancias, grados, disonancias, etcétera), tal como van apareciendo en la teoría, permite la formulación de equivalencias entre sonidos, números y afecciones, $i$. e., la quinta equivale tanto a $2 / 3$ como la consonancia más agradable que existe.

\section{Mecanicismo}

En la filosofía cartesiana se postulan relaciones causales, necesarias y sistemáticas entre todas la partes de la extensión. En la teoría musical de Descartes, las relaciones entre sonidos y oídos también se entienden de manera mecánica. En efecto, la razón de que ciertos sonidos sean percibidos de cierta manera depende de los choques de la materia y las leyes del movimiento, y no de la

${ }^{15}$ R. Descartes, "Compendium musicae", en Ouvres de Descartes, vol. x, cap. 1, p. 90. La traducción es mía. 
voluntad o inclinación personal del escucha. De ahí la pertinencia de clasificar todos y cada uno de los movimientos del alma que son provocados por la música; basta con identificar qué afecto en específico es excitado por cada tipo de compás, consonancia, grado, disonancia, etcétera, esto es, debido a los efectos que el tiempo y la intensidad del sonido producen, de manera natural, en los oídos; sólo hay que considerar, pues, qué tan rápido y qué tan intenso es el movimiento de las partículas que chocan con los oídos para determinar el tipo de afecto que, en consecuencia, ha de surgir en el alma. En el Compendium musicae, la clasificación de afectos según el tiempo y la intensidad del sonido no será realizada a cabalidad, por resultar demasiado amplia para un compendio, ${ }^{16}$ sin embargo, será retomada en textos posteriores.

La idea de un mecanicismo que involucra objetos, sentidos y afectos o pasiones está presente en varios textos de Descartes. ${ }^{17}$ Sin embargo, esta idea no parece comprensible a partir del mecanicismo de la extensión en general, es decir, como simple derivación o subespecie suya, ya que implica un elemento esencialmente distinto -y bastante más problemático- que cualquier cuerpo o parte de la extensión. En efecto, los oídos no perciben todos y cada uno de los movimientos o choques de la materia. En general, los sentidos no tienen la capacidad de procesar todos los insumos sensibles sino sólo aquellos que resultan significativos para el alma ${ }^{18}$ Hay, pues, una especie de "selección espiritual" para descartar aquellos movimientos que serían, en

${ }^{16}$ Por ejemplo, los compases lentos excitarán movimientos lentos, como la tristeza, el miedo y la soberbia; los compases rápidos, al contrario, excitarán movimientos rápidos, como la alegría (cf. ibid., p. 95).

${ }^{17}$ En el Tratado del hombre, Descartes sostiene que el órgano del sentido auditivo consiste en filamentos situados en el fondo de las concavidades de los oídos, y "dispuestos de tal manera que pueden ser movidos con facilidad y de una misma forma por pequeñas sacudidas del aire, en cuanto este último choca contra una delicada piel que permanece tensa en la entrada de dichas concavidades" (R. Descartes, Tratado del hombre. Madrid, Alianza, 1990, p. 55). Al respecto, en los Principios de la filosofía agrega lo siguiente: "Los nervios escondidos en el interior de los oídos siguen todas las vibraciones de los movimientos del aire circundante [...] cuya diversidad de movimientos origina la diversidad de las sensaciones de sonidos" (R. Descartes, "Principia philosophiae", en Ouvres de Descartes, vol. vIII, principio núm. 194). Finalmente, en Las pasiones del alma confirma la propuesta que ya encontramos en el Compendium: "A fin de enumerar las pasiones, sólo hay que considerar ordenadamente de cuántas maneras distintas que nos importen pueden nuestros sentidos ser movidos por los objetos que les corresponden" (R. Descartes, "Artículo 52, segunda parte", en Las pasiones del alma. Barcelona, Península, 1972).

18 "Advierto que los objetos que mueven los sentidos no excitan en nosotros diversas pasiones en razón de todas las variedades que hay en ellos, sino únicamente con arreglo a los modos diversos con que pueden dañarnos o aprovecharnos, o en general, ser importantes" (idem.) 
principio, sensibles o perceptibles para los sentidos, pero que, sin embargo, resultan inapropiados o inútiles para el alma; ${ }^{19}$ de manera que la causalidad no va a operar sino en relación con la voluntad. Así, pues, la justificación del mecanicismo de objetos, sentidos y afectos se dificulta por la intervención de la voluntad. Y como veremos más adelante, en el Compendium musicae se ofrece la solución de esta dificultad mediante un supuesto que, no obstante, no volverá a ser confesado por Descartes.

\section{Contenido del Compendium musicae}

El Compendium musicae consta de catorce secciones que podemos agrupar de la siguiente manera: (i) los principios o fundamentos que se exponen en las primeras dos secciones; (ii) el análisis del sonido musical que ocupa las siguientes nueve secciones, $\mathrm{y}$ (iii) las reglas de composición que se establecen en las últimas dos secciones. La argumentación procede, en general, mediante definiciones, deducciones, axiomas y operaciones matemáticas, aunque también se recurre a inducciones y analogías, así como a descripciones empíricas y figuras retóricas, puesto que se pretende una justificación empírica, además de racional, de esta teoría musical.

\section{Fundamentos de la teoría musical}

En la primera sección se presenta el objeto de estudio del Compendium musicae, a saber, el sonido cuya finalidad consiste en mover varios de nuestros afectos. Se distinguen dos "afecciones sonoras": el tiempo o duración, y la fuerza o intensidad. Asimismo, se establecen los criterios mencionados ${ }^{20}$ para clasificar sonidos según su conformidad con el espíritu humano.

En la segunda sección se encuentran las siguientes notas previas:

1. Todo sentido es susceptible de ser deleitado.

2. El deleite implica cierta proporción del objeto con el sentido en cuestión.

3. Si el objeto es muy confuso o difícil de percibir, entonces no puede deleitar.

4. El objeto es más fácil de percibir en cuanto la diferencia de sus partes es menor.

19 "[...] el uso de las pasiones [consiste] solamente en que dispone al alma a querer las cosas que la naturaleza nos enseña que son útiles y a persistir en esta voluntad, a la manera que la misma agitación de los espíritus, que suele causarlas, dispone el cuerpo para los movimientos que sirven para ejecutar estas cosas" (idem.).

${ }^{20}$ Vid. supra Matematización, i-ii, p. 138. 
5. Las partes cuya diferencia es menor son aquellas entre las que hay mayor proporción.

6. Esta proporción debe ser aritmética (o discreta) y no geométrica (o continua), de manera que el sentido pueda distinguir las diferencias.

7. Los objetos del sentido que más agradan al alma son aquellos que no resultan muy fáciles ni muy difíciles de percibir.

8. En todo caso, la variedad es de lo más agradable.

\section{Análisis del sonido musical}

En la tercera y cuarta sección se aborda el tiempo y la intensidad, respectivamente. En ambos casos se trata de comprender el comportamiento del sonido a partir de sus elementos -temporales e intensionales- más simples, así como de establecer los límites de la complejidad que es pertinente alcanzar mediante ellos. Para tales efectos, se postulan dos medidas temporales: la cuadrada-que responde a la proporción doble- y la terciada -que responde a la proporción triple-, cuyas combinaciones darían lugar a muchas otras proporciones que, sin embargo, no son recomendables si también hay variación de intensidad. En cuanto a la intensidad no se requiere, en principio, más que la división del unísono, sin consideración del tiempo en el que éste es emitido, con lo cual empieza el estudio de las consonancias.

En la quinta sección se abordan las consonancias, que constan de dos términos - uno grave y otro agudo- que suenan a la vez, entre los cuales se observaría la proporción numérica correspondiente (1/2 para una octava; $2 / 3$ para una quinta; $4 / 5$ para un ditono; etcétera). Pero en cuanto se presentan variables temporales e intensionales, ya sea cuando una voz canta a capella, o bien, cuando varias voces emiten melodías distintas al mismo tiempo, entonces se requieren grados y disonancias, además de consonancias.

La sexta sección versa sobre la octava. Es la primera de todas las consonancias porque representa la proporción más simple y fácil de percibir, a saber, la proporción doble. En efecto, la octava surge inmediatamente por la primera división del unísono, y todas las demás surgirán por la subsecuente división de la octava, o bien, por la suma de sus partes. A partir de la primera consonancia es posible clasificar todas las demás, según sean generadas con propiedad o por accidente. Entre las consonancias "propias" se encuentra, pues, la octava, que se genera por sí misma; la quinta, que se genera inmediatamente después, por la división de la octava; así como el ditono, que se genera por la división de la quinta. Todas las demás se generan por accidente.

La séptima sección versa sobre la quinta, que representa la proporción triple. De las tres consonancias generadas con propiedad, la quinta es la que ocupa el lugar de en medio, pues no es tan fácil de percibir como la octava 
(que corresponde a la proporción doble) ni tan difícil como el ditono (que corresponde a la proporción quíntuple); de ahí que sea la más agradable de todas las consonancias. ${ }^{21}$ Las consonancias que faltan (la cuarta, el ditono, la tercera menor y la sexta) se abordan en la octava y la novena sección en el orden que les corresponde por lo dicho.

La décima sección versa sobre los grados o tonos musicales, es decir, los intervalos que se generan cuando hay variables temporales e intensionales. Los grados también se obtienen por la división de la octava en partes iguales, puesto que han de moderar las inequidades que puedan presentarse entre las consonancias que se han derivado de la octava. Ya que el tiempo o la sucesión de sonidos tiene lugar entre notas emitidas por distintas voces, o bien, entre notas emitidas por una misma voz, según se trate de polifonías o de melodías, en efecto, los grados o tonos se ocuparán para moderar las diferencias entre consonancias y son relativos a ellas, o bien, para moderar las diferencias entre sonidos emitidos por una misma voz. En general, las melodías no son tan largas ni tan variadas como para que los grados extraídos de la octava sean insuficientes, sin embargo, hay que aceptar una posible progresión más allá de los grados establecidos, así como la movilidad de términos en algunas circunstancias.

La décima primera sección se dedica a las disonancias, es decir, aquellos intervalos que, a pesar de ser inequitativos e indeseables, no pueden ser evitados en la composición musical. Y es que la música puede ser emitida por varias voces que suenan al mismo tiempo, de manera que se observan diferencias entre notas simultáneas - por el hecho de que distintas voces suenan al mismo tiempo-y diferencias entre notas sucesivas - puesto que cada una de las voces emite distintas notas-, se observan, pues, dos tipos de diferencias a la vez, lo cual puede implicar mucho trabajo para los oídos, es decir, dificultad para el escucha y dolor para el alma. Sin embargo, cuando las disonancias sean colocadas en lugares adecuados, en tal caso, el efecto será plenamente satisfactorio, ya que aumentará la variedad. Ni siquiera las disonancias más ingratas como el tritono (32/45) o la falsa quinta (45/64) quedarán completamente excluidas de la composición musical; sobre todo en canciones de ritmo rápido y acelerado, puesto que, si tales disonancias suenan por breves intervalos de tiempo, el escucha no alcanzará a percibir la proporción tan difícil y confusa que ahí es generada sino que, por el contrario, concebirá cierta unidad muy variada, y obtendrá la deseada sensación de novedad. ${ }^{22}$

${ }^{21}$ Vid. supra Fundamentos de la teoía musica, 7, p. 141.

${ }^{22}$ Vid. supra ibid., 8, p. 141. 


\section{Reglas de la composición musical}

En la décima segunda sección se exponen las reglas de la composición musical a partir del análisis del sonido. Descartes establece dos niveles de regulación: 1) el más seguro consiste en colocar consonancias sucesivamente junto con los grados correspondientes, evitando cualquier disonancia y, en especial, el tritono y la falsa quinta y 2) el más arriesgado permite incluir disonancias mediante técnicas de disminución y síncopa. Además de lo anterior, para mayor elegancia, estilo y variedad en la composición, es menester identificar las cuatro partes de la sinfonía: $i$ ) el Bajo, que es la voz principal y no debe moverse más que por intervalos consonantes; ii) el Tenor, que se ocupa de mantener la cohesión entre las distintas partes, para lo cual ha de moverse por grados; iii) el Contratenor, que sólo se incluye para aumentar la variedad, y que también debe moverse por intervalos consonantes pero siempre con respecto al Tenor, y $i v$ ) la Soprano, que también se mueve por grados, pero siempre con respecto al Bajo.

Finalmente, en la décima tercera sección se hace mención de los modos, que se refieren a las diversas formas correctas de organizar intervalos sonoros. En efecto, los modos predeterminan la armonía de muchos tipos de canciones y comprenden múltiples variaciones, dando paso a la deseada sensación de novedad, esto es, sin eliminar la unidad de cada canción ni renunciar al orden del espectro de posibilidades sonoras. Según Descartes no es necesario decir gran cosa al respecto, ya que los músicos tienen pleno dominio de los modos. Además, todo lo que saben de este asunto puede ser explicado a partir de lo dicho en las secciones anteriores, y en caso de que surgiera algo más, algo que hasta ahora no ha sido contemplado, ellos podrán resolverlo por sí mismos, si es que se basan en los fundamentos, elementos y reglas que han sido expuestos y justificados en el Compendium musicae. ${ }^{23}$

\section{La confesión de Descartes}

El Compendium musicae contiene los fundamentos teóricos de la composición musical correcta en términos racionales (según proporciones aritméticas) y sensibles (agradable a los oídos). La combinación -quizá confusión- del científico y el músico a través del filósofo depende que este último conserve criterios, valores y presupuestos que son independientes de la naturaleza del sonido, ${ }^{24}$ esto es, con el fin de comprender el fenómeno en cuestión. Para

${ }^{23}$ Vid. supra Deductibilidad, iii, p. 137.

${ }^{24}$ Vid. supra Matematización, i, p. 138. 
ello, sin embargo, tiene que hacer una especie de confesión respecto a cierta relación de la fuerza "objetiva" del sonido con la valoración "subjetiva" del escucha. Se trata de una confesión porque esta relación no puede ser deducida ni explicada mediante ejemplos. Simplemente hay que suponer que la fuerza original u objetiva del sonido se transforma en pensamientos equivalentes, ${ }^{25}$ de ahí que la cantidad asignada a cada sonido permita identificar los efectos que produce en el escucha. Así es como la rítmica de la música puede ser entendida mediante la arritmia de las matemáticas. Así es como se explica, por ejemplo, la medición del tiempo fuerte o el inicio de cada compás, que es la primera medición del Compendium musicae. En efecto, la fuerza del primer golpe -considerablemente mayor que la de todos los demás- no sólo repercute en los oídos sino también en las almas o el espíritu:

[...] que sea confesado algo más con respecto a este asunto: cuando decimos que el sonido es emitido con más fuerza y distinción al inicio de cada compás suponemos que va a repercutir con la misma fuerza en nuestros espíritus, por lo que somos excitados al movimiento. De ahí que las fieras también puedan saltar a tiempo, si son instruidas y se acostumbran a ello, simplemente por la naturaleza de su instinto. ${ }^{26}$

Esta confesión puede llevarnos a la siguiente confusión: la fuerza del sonido que repercute en los espíritus termina por identificarse con el número y la afección correspondientes; la extensión de la materia se confunde, pues, con la existencia del pensamiento; como si la quinta significara, por ejemplo, cierta relación entre sonidos (que a la postre resulta de lo más agradable para los oídos) al igual que cierta proporción numérica (ni muy fácil ni muy difícil de pensar) y cierta cualidad afectiva (de lo más satisfactoria para el alma). Así es que algunas cualidades de la materia (como son el tiempo y la intensidad del sonido) serían comunicadas al alma, ${ }^{27}$ de manera que la diversidad de so-

${ }^{25}$ Gracias a la transformación de sonidos en números es posible identificar cualquier elemento sonoro en el marco de cualquier composición sin tener que reproducirlo ni considerar opiniones o experiencias al respecto. Esta transformación es injustificable a partir de razones deductivas, pero es gracias a ella que la teoría de la música puede avanzar a pesar de los siguientes problemas: (i) que la fuerza de los sonidos varía constantemente junto con nuestra capacidad de escucharlos, mientras que las proporciones numéricas se mantienen iguales; (ii) que no todos tenemos el mismo sentido, mientras que todos hacemos las mismas operaciones matemáticas; (iii) que el oído suele ser obstruido o confundido, mientras que los números mantienen su propia claridad y distinción.

${ }^{26}$ R. Descartes, "Compendium musicae", en Ouvres de Descartes. vol. x, cap. 3, p. 95. La traducción es mía.

${ }^{27}$ En los Principios de la filosofía se mantiene una concepción muy similar de la percepción sensible: "Empero, los movimientos del cerebro, que son excitados por los 
nidos -agudos, graves, lentos, rápidos, etcétera- producidos por el músico correspondería a la diversidad de afectos -alegría, tristeza, etcétera- padecidos por el escucha.

La transformación de sonidos en números se presenta como un proceso de racionalización inexplicable, natural o intuitivo. El filósofo parece proceder como el músico que cuenta el tiempo y organiza las notas mientras toca, esto es, sin cuestionar la supuesta equivalencia entre sonidos y números: sin dudar de la estrecha relación que existe entre lo que piensa y lo que siente, ya que no quiere perder el ritmo. El hecho es que músicos y escuchas se comunican a través del sonido sin necesidad de recurrir a justificaciones, definiciones o determinaciones explícitas, lo que bien puede ser explicado si suponemos que ambos comprenden el fenómeno mediante razonamientos matemáticos, aunque sea intuitivamente, y aunque resulte imposible demostrar que la fuerza de cada sonido emitido por el músico es exactamente igual a la cantidad o cualidad que el filósofo le asigna. Dicha equivalencia se mantendrá, en el Compendium musicae, a modo de confesión: una supuesta relación entre sustancias que Descartes no volverá a confesar, y que más adelante se dará a la tarea de evitar en la empresa más costosa y criticada de toda su doctrina filosófica.

\section{El dualismo cartesiano ${ }^{28}$ y el Compendium musicae}

Hemos dicho que la opinión de Descartes sobre la pertinencia de dedicarse a cuestiones estéticas cambió entre la juventud y la madurez, o bien, que su

nervios, afectan de diverso modo, dada la misma diversidad de aquellos, al alma o a la mente, que están estrechamente unidas al cerebro. Y así es como estas diversas afecciones o pensamientos de la mente se siguen inmediatamente de aquellos movimientos en las llamadas percepciones sensibles, o bien, en el sentido, como comúnmente dicen" (R. Descartes, "Principia philosophiae", principio núm. 189, en Ouvres de Descartes, vol. VIII).

${ }^{28}$ Respecto a la doctrina del dualismo y la comunicabilidad de las substancias han surgido tantas discusiones e interpretaciones en la Historia de la Filosofia que bien podríamos suscribir, tan sólo para este asunto, lo que dice Margaret Wilson sobre el estudio de la filosofía cartesiana en general: "hay tantos libros que sólo podría asimilarlos en el espacio de una vida un especialista casi maniático" (Margaret Wilson, Descartes. Trad. de José Antonio Robles. México, UNAM, 1990, p. 5). Lejos de ofrecer un tratamiento exhaustivo del asunto nos interesa comprender y contextualizar la confesión de Descartes que hemos señalado en el apartado anterior. Para tales efectos basta con decir lo siguiente. La distinción entre substancias ocupa un lugar fundamental en la filosofía cartesiana. Sólo existen dos substancias creadas por Dios: el cuerpo cuyo atributo principal es la extensión, y la mente cuyo atributo principal es el pensamiento. En los Principios de la filosofía, la substancia se define a como aquello que existe de manera independiente, es decir, que no necesita de nada -más que del concurso de Dios- para existir ( $c f$. $\mathbf{R}$. 
pensamiento es completamente sistemático y no existe tal cambio. Para saber cual es el caso es necesario elaborar una interpretación de su teoría musical a la luz de la filosofía cartesiana en general. Ahora bien, respecto a la doctrina del dualismo hemos notado que la distinción entre sustancias es un elemento constante y fundamental en la filosofía cartesiana, pero que, sin embargo, este asunto adquiere un tratamiento bastante peculiar en el Compendium musicae, diferente al que encontramos en otros textos del mismo autor. En efecto, en la obra de Descartes abundan los argumentos especialmente diseñados para hacernos dudar de los sentidos, así como del conocimiento del mundo externo que depende de ellos. Dichos argumentos podrán parecernos más o menos convincentes; algunos dirán que carentes de seriedad, rigor o veracidad, pero el problema de fondo es claro: "El interés de Descartes - dice Laura Benítez- es demostrar que los sentidos no son del todo confiables, pues si bien es verdad que los objetos producen modificaciones en nuestro espíritu, éstas, en tanto ideas sensibles, no reproducen las características esenciales de aquellos". ${ }^{29}$ Por el mecanicismo del mundo externo es preciso sostener que existe una relación causal entre los objetos y las sensaciones que les corresponden; pero es necesario recalcar que "las ideas de sensación no reproducen las características esenciales de los objetos". ${ }^{30}$ Así, pues, todas las dudas en torno a una supuesta relación de objetos y sensaciones no tienen la finalidad de negar dicha relación, ni de eliminar la causalidad que impera en el mundo y cancelar la búsqueda de conocimiento. Descartes intenta reafirmar el principio metafísico del dualismo con el fin de obtener cada vez más y mejor conocimiento del mundo, del alma y de Dios. Para lo cual es necesario sostener que "nada en absoluto está incluido en el concepto de cuerpo que pertenezca a la mente y nada en el concepto de mente que pertenezca al cuerpo". ${ }^{31}$

Descartes, "Principia philosophiae", principio núm. 52-53, primera parte, en Ouvres de Descartes, vol. VIII). En ese tenor, en las Meditaciones metafísicas se afirma que toda sustancia es incorruptible por naturaleza, puesto que nada puede impedir que exista como tal. De ahí que la substancia extensa y la substancia pensante constituyan -por la sola definición de substancia- existencias distintas, independientes e incorruptibles ( $c f$. R. Descartes, "Meditationes de prima philosophia", sección 2, en Ouvres de Descartes, vol. VII). Ahora bien, Descartes sostiene que es imposible conocer los atributos de ambas sustancias, así como acceder a todo lo que de ahí puede ser deducido (es decir, prácticamente todo lo que el ser humano puede conocer), mientras no sean concebidas con perfecta claridad y distinción. Si esto último no ocurre, en efecto, ni siquiera se tiene certeza sobre la propia existencia. Así, pues, la confusión entre sustancias se presenta como uno de los errores más comunes y perjudiciales del pensamiento humano, un error que la filosofía cartesiana tratará de señalar, evitar y corregir.

${ }^{29}$ L. Benítez, "La res extensa como mundo externo en Descartes", en Dianoia. México, unam, 1986, núm. 32, p. 28.

${ }^{30}$ Idem.

${ }^{31}$ R. Descartes, "Compendium musicae", en Ouvres de Descartes, vol. x, cap. 3, p. 95. 
Si bien es cierto que en el Compendium musicae no se encuentran referencias explícitas a la sustancia extensa, la sustancia pensante o la distinción entre sustancias, a partir del estudio que hemos realizado es posible identifcar relaciones entre aquello que Descartes identificará en obras posteriores como sustancias creadas. La teoría musical de Descartes descansa, pues, en la confusión de ciertas partes del cuerpo con ciertas partes de la mente, ya que, según su propia confesión, la fuerza del sonido (que formaría parte del cuerpo) se transforma en afectos (que formarían parte de la mente), y ambos son equivalentes, al menos en el campo de la teoría musical.

A hora bien, ¿es pertinente que interpretemos esta confesión metodológica como una confusión ontológica? Supongamos que sí. Entonces podríamos dar una explicación plausible del cambio de opinión de Descartes respecto al estudio de la música. Más allá de descubrir el carácter subjetivo e irracional del asunto, la razón de su renuncia radicaría en la dificultad de sostener una hipótesis tan problemática; una hipótesis que, por lo demás, resulta innecesaria y perjudicial para el conocimiento de todo lo que el ser humano quiere y puede conocer, además de la música.

La confesión de Descartes podría ser necesaria para el desarrollo de su teoría musical, a la vez que innecesaria e imposible de justificar en el marco de la filosofía cartesiana en general; bien podría consistir en una hipótesis que permite la producción y adquisición de conocimientos en una y sólo en una de las materias que existen, aunque puede y debe ser abandonada en cuanto se trate de cualquier otro asunto. Todo lo que se explica en el Compendium musicae mediante equivalencias entre sonidos y afectos puede ser explicado en otras partes de la filosofía cartesiana sin recurrir a tales equivalencias, con la obvia excepción de la música. Los sonidos y los afectos podrían ser completamente distintos y existir efectivamente separados, la idea de que unos son causa de los otros podría ser una ficción de la imaginación, y todas las denominaciones de la teoría musical en cuestión (intervalos, notas y reglas de composición) podrían ser triviales o irrelevantes, sin embargo, ni el comportamiento del sonido específicamente musical, ni las reacciones corporales del escucha, aquel que se considera más o menos deleitado, más o menos satisfecho, más o menos agradecido por la música, dejarían de ser cognoscibles a partir de los mismos fundamentos y elementos de la filosofía cartesiana. ${ }^{32}$

${ }^{32}$ Podemos encontrar el esbozo de esta idea entre los remedios para el alma que ofrece Descartes a Isabel de Bohemia: "Se me ocurre que aquí puede verse fácilmente la diferencia entre el entendimiento y la imaginación o el sentido; pues es tal que creo que una persona que, sin tener motivo alguno de descontento, presenciara continuamente representaciones de tragedias, en las que no acontecieran sino cosas funestas, y sólo se ocupara de tristezas y penas, aun sabiéndolas fingidas y fabulosas, de forma tal que lo moviesen a continuo llanto y le conmovieran la imaginación sin participación del en- 


\section{Conclusión}

En este artículo he tratado de sostener que en el Compendium musicae se establecen determinadas relaciones entre el sujeto y el objeto que pueden ser precisadas, según el autor, con base en razonamientos aritméticos, es decir, mediante operaciones que implican cantidades discontinuas, a pesar de que se trate de fenómenos temporales, o bien, de cantidades continuas que producen afecciones muy variadas, para las cuales no existe un vocabulario estandarizado. Para tales efectos, lo primero que se aclara es que el objeto de estudio es el sonido, pero no tenemos elementos suficientes para determinar si se trata del sonido en general o solamente del sonido musical, o bien, como creo que es el caso, de ambos al mismo tiempo. Con decir que el músico altera el movimiento constante y natural del sonido a manera de producir placer, deleite, provecho o satisfacción, ya podemos identificar el sonido propiamente musical. Lo anterior implicaría, pues, el concurso de la voluntad humana. Sin embargo, según la teoría musical de Descartes, una composición es más racional o correcta en la medida en que se adecua a la naturaleza del sonido y a la de los oídos. Si una composición nos parece agradable es porque en ella se mantienen las proporciones que por naturaleza nos agradan, no siendo más que las proporciones características del sonido natural, es decir, aquellas que se observan entre las partes del sonido en la medida en que éste se descompone, transcurre o resuena en el tiempo. En este sentido, lo único que podría complicar el estudio del sonido musical (tal como de hecho sucede, al grado de ocupar una parte especial y sui generis en el marco de la filosofía cartesiana) es la unidad en la variedad, así como la sensación de novedad que le acompaña; justo aquello que, a la postre, resulta de lo más agradable, esperado y procurado en el mundo de la música.

tendimiento, creo, digo, que sólo con eso bastaría para que el corazón se acostumbrase a sentirse oprimido y para andar entre suspiros; con lo que se retrasaría y demoraría la circulación de la sangre, y las partes más groseras de ésta podrían trabarse entre sí y obstruir el bazo, entorpeciéndose y deteniéndose en sus poros. Y las partes más sutiles, al refrenar su movimiento, podrían alterar los pulmones y causar a esa persona una tos que, a la larga, resultaría muy perniciosa" (R. Descartes, "Correspondencia con Isabel de Bohemia", en Descartes, vol. II. Trad. de María Teresa Gallego. Barcelona, Gredos, 2014, p. 339). 